\title{
Endoskopik sfinkterotomi sonrası kanama: Tek merkezli retrospektif çalışma
}

\author{
Bleeding after endoscopic sphincterotomy: A single-center retrospective study
}

Nuretdin SUNA ${ }^{1}$, Bülent ÖDEMIŞ², Selçuk DIŞİBEYAZ³, Erkin ÖZTAŞ², Ufuk Barış KUZU², Hakan YILDIZ Muhammet Yener AKPINAR², Diğdem ÖZER ETİK ${ }^{1}$, Erkan PARLAK ${ }^{5}$

${ }^{1}$ Başkent Üniversitesi Tip Fakültesi, Gastroenteroloji Bilim Dall, Ankara

${ }^{2}$ Türkiye Yüksek Ihtisas Eğitim ve Araştırma Hastanesi, Gastroenteroloji Kliniği, Ankara

${ }^{3}$ Eskişehir Osmangazi Universitesi Tip Fakültesi, Gastroenteroloji Bilim Dall, Eskişehir

${ }^{4}$ Biruni Universitesi Tip Fakültesi, Gastroenteroloji Bilim Dall, Istanbul

${ }^{5}$ Sakarya Üniversitesi Tip Fakültesi, Gastroenteroloji Bilim Dall, Sakarya

Giriş ve Amaç: Endoskopik retrograt kolanjiyopankreatografi, pankreatobiliyer hastalıklarda etkin bir tanı ve tedavi aracı olmakla beraber ciddi komplikasyonlara sahip olan invaziv bir işlemdir. Endoskopik retrograt kolanjiyopankreatografiişleminin önemli komplikasyonlarından biri kanamadır. Retrospektif olarak tek merkezde yapılan bu çalışmanın amacı,endoskopik sfinkterotomi sonrası kanamanın sıklığını, derecesini, tipini, risk faktörlerin ve uygulanan tedavi yöntemlerini belirlemektir. Gereç ve Yöntem: Ocak 2008-Nisan 2013 tarihleri arasında merkezimizde çeşitli endikasyonlar ile endoskopik retrograt kolanjiyopankreatografi yapılan hastalara ait kayıtlar retrospektif olarak incelendi. Bu süre arahı̆ında endoskopik retrograt kolanjiyopankreatografi yapılan toplam 12.893 hastadan endoskopik sfinkterotomi yapılan naiv papillalı 6552 hasta vardı. Endoskopik sfinkterotomi sonrası kanama gelişen hastalar çalışma popülasyonunu oluşturdu. Bulgular: Endoskopik sfinkterotomi yapilan hastaların 81'inde (\%1.23) kanama saptandi. Hastaların 46'sı (\%56.8) kadın ve 35'i (\%43.2) erkek idi. Yas ortalaması 64.9 (18-89) yıl olarak saptandl. Erken kanama 50 (\%61.7) ve geç kanama 31 (\%38.3) hastada görüldü. Kanama derecesi 53 (\%65.4) hastada hafif, 21 (\%25.9) hastada orta ve 7 (\%8.6) hastada siddetli saptand. Hastaların 4l'ine (\%50.6) epinefrin enjeksiyonu, 25'ine (\%30.8) epinefrin enjeksiyonu ile heater probu kombinasyonu, 7'sine (\%8.6) heater probu, 2'sine (\%2.4) balon tamponadı, 3'üne (\%3.7)'üne balon tamponadı ile epinefrin enjeksiyon kombinasyonu, 2'sine (\%2.4) tam kaplı metalik stent ve l'ine (\%1.2) hemoklips uygulandı. Endoskopik sfinkterotomi kanaması gelişen bu hastalarda cerrah gereksinim ve mortalite olmadi. Sonuç: Endoskopik retrograt kolanjiyopankreatografi işleminin önemli komplikasyonlarindan biri olan kanama, eski çalışmalara göre günümüzde insidansı azalmakla birlikte halen önem arzetmektedir. Çalışmamızda, son yıllarda literatürde bildirilen endoskopik sfinkterotomi sonrası kanama oranlarina benzer oranda (\%1.23) saptand1. Aynı zamanda çalışmamız, endoskopik sfinkterotomi sonrası kanamalara erken tanı ve zamanında müdahalenin önemli olduğunu göstermektedir.

Anahtar kelimeler: Endosokopik sfinkterotomi, komplikasyon, kanama

\section{GİRIS}

Endoskopik retrograt kolanjiyopankreatografi (ERKP), 1968 ylında ilk kez kullanılmaya başlanmıştır (1). Günümüzde biliyer ve pankreatik patolojilerin tedavi ve tanısında yaygin olarak kullanılmaktadır (2-4). ERKP bilgi, beceri ve tecrübe
Background and Aims: Endoscopic retrograde cholangiopancreatography is an effective diagnostic and therapeutic method; however, its invasive nature can lead to serious complications, including bleeding. The primary aim of this retrospective study, which was performed in a tertiary reference center, was to demonstrate the frequency, severity, and types of post-endoscopic sphincterotomy bleeding, identify the risk factors of post-endoscopic sphincterotomy bleeding, and determine the appropriate treatments for these patients. Material and Methods: Medical information on patients treated with endoscopic retrograde cholangiopancreatography between February 2008 and April 2013 was examined retrospectively. In this period, a total of 12,893 patients were detected; 6552 of them had no previous endoscopic retrograde cholangiopancreatography history. Patients with bleeding after endoscopic sphincterotomy were included in the study. Results: The frequency of bleeding after endoscopic sphincterotomy was $1.23 \%$ (81 patients). The mean patient age was 64.9 (18-89) years, 46 patients were women (56.8\%), and 35 patients were men (43.2\%). Immediate bleeding was observed in $50(61.7 \%)$ patients, and delayed bleeding was observed in 31 (38.3\%) patients. Most bleeding episodes were mild (53 patients, 65.4\%), moderate bleeding was seen in 21 patients (25.9\%), and severe bleeding was seen in $7(8.6 \%)$ patients. Epinephrine injection alone was the most frequent treatment method (41 patients, 50.6\%), followed by epinephrine injection plus heater probe (25 patients, 30.8\%), heater probe alone ( 7 patients, 8.6\%), epinephrine injection plus balloon tamponade ( 3 patients, $3.7 \%$ ), balloon tamponade alone (2 patients, $2.4 \%$ ), self-expandable full covered metal stent ( 2 patients, $2.4 \%$ ), and endoclips alone (1 patient, $1.2 \%$ ). These patients did not require surgery, and mortality was not observed. Conclusion: To date, the frequency of post- endoscopic sphincterotomy bleeding is lower than reported by older studies; nonetheless, bleeding is an important complication of endoscopic retrograde cholangiopancreatography. We found a $1.23 \%$ frequency of post-endoscopic sphincterotomy bleeding, in agreement with previous literature. Our study also demonstrates the importance of early diagnosis and prompt treatment of this complication.

Key words: Endoscopic sphincterotomy, complication, bleeding

gerektiren kompleks bir endoskopik uygulamadır. Diğer endoskopik işlemlere göre daha farklı teknik ve ekipman gerektirmektedir. Ayrıca daha fazla komplikasyon görülmektedir. Bu nedenle günümüzde terapötik amaçla daha çok kullanıl- 
maktadır. ERKP sonrası gelişen kanama öncelikle terapötik ERKP'nin köşe taşı olan endoskopik sfinkterotomi (ES) ile ilişkili bir komplikasyondur. Eski çalışmalarda ES sonrası kanama insidansı \%2-5 olarak raporlanmıştır (5). Yakın zamanda yayınlanan 21 prospektif çalışmanın meta-analizinde, ES sonrası kanama oranı \% 1.3 oranında bildirilmisstir (6). ES, ERKP sonrası kanama için bağımsız bir risk faktörü olmakla birlikte, çok değişken analizlerde tanımlanan diğer faktörler ise koagülopati, antikoagülan kullanımı, akut kolanjit veya papiller stenoz varlığı, ön kesi yapılması ve endoskopistin düşük vaka hacmine (haftada bir veya daha az ES) sahip olmasıdır (7-9). Retrospektif olarak tek merkezde yapilan bu çalışmanın amacı, ES sonrası kanamanın sıklı̆ı̆ını, derecesini, tipini, risk faktörlerini ve uygulanan tedavi yöntemlerini belirlemektir.

\section{GEREC ve YÖNTEM}

Ocak 2008-Nisan 2013 tarihleri arasında Türkiye Yüksek Ihtisas Hastanesi ERKP ünitesinde çeşitli endikasyonlar ile ERKP yapilan hastalara ait kayitlar retrospektif olarak incelendi. $\mathrm{Bu}$ süre aralığında ERKP yapılan toplam 12.893 hastadan ES yapılan naiv papillalı 6.552 hasta vardı. ES sonrası kanama gelişen hastalar çalışma popülasyonunu oluşturdu. Başka bir merkezde yatarken kliniğimizde ERKP işlemi yapılan ve sağllkl şekilde verilerine ulaşılamayan hastalar çalışma dışı bırakıldı. ERKP işlemleri deneyimli 3 endoskopist tarafindan Olympus videoduodenoskop (Olympus TJF 240, Japan, 4.2 mm çalışma kanallı) ile gerçekleştirildi. Kliniğimizde hastalara işlem öncesi \%10'luk lidokain sprey ile boğaz anestezisi ve kontrendikasyon yoksa işlem esnasında midazolam ve meperidin ile bilinçli sedasyon uygulanmaktadır. Duodenal peristaltizm ise intravenöz Hyoscine N-butilbromür ile inhibe edilmektedir.

Çalışmaya alınan hastaların demografik verileri, laboratuvar bulguları, komorbid durumları, antikoagülasyon ve antiagregan ilaç kullanımları, ERKP endikasyonları, periampüller divertikül varlığı, kanamanın tipi (erken, geç), eritrosit süspansiyonu transfüzyon ihtiyacı, kanamanın derecesi (hafif, orta, şiddetli) ve yapılan tedaviler kaydedildi.

ES sonrası gelişen kanama hafif, orta ve şiddetli olarak derecelendirildi (5). Hafif kanama; sadece endoskopik olarak değil, klinik olarak da kanama kanıtı olan, transfüzyon ihtiyacı olmayan ve hemoglobinde $3 \mathrm{gr} / \mathrm{dl}$ 'den az düşüş olan kanama, orta şiddette kanama; dört ünite veya daha az eritrosit süspansyon transfüzyonu ihtiyacı olması ve angiografik veya cerrahi girişim ihtiyacının olmaması, şiddetli kanama; beş ünite ve daha fazla eritrosit süspansiyon transfüzyonu ihtiyacı veya angiografik veya cerrahi girişim ihtiyacının olması olarak tanımlandı. ES'den hemen sonra gelişen kanama "erken kanama" ve işlemden 24 saat sonra görülen kanama "geç kanama" olarak tanımlandı.

ES sonrası kanama gelişen bu hastaların endoskopik tedavi- sinde, skleroterapi iğnesi kullanılarak serum fizyolojik çözeltisi ile seyreltilmiş epinefrin (1/10000) enjeksiyonu, heater probu ve her ikisinin kombinasyonu en sık kullanılan yöntemlerdi. Diğer nadir kullanılan endoskopik tedavi yöntemleri ise hemoklips, balon tamponadı ve tam kaplı metalik stent uygulamass idi.

Istatistik analizler SPSS 20.0 (SPSS Inc., Chicago, IL, USA) programı kullanılarak yapıldı. Değişkenlerin normal dağılım uygunluğu görsel (histogram ve olasıllk grafikleri) ve analitik yöntemlerle (Kolmogrorov-Smirov-Shapiro-Wilk testleri) incelendi. Normal dağılmayan değişkenler için ortanca ve çeyrekler arası kullanılarak verildi. Karşılaştırmalarda nonparametrik değişkenler karşılaştırmalarında Mann-Whitney U testi kullanıldı. P değeri <0.05 anlamlı kabul edildi.

\section{BULGULAR}

Çalışma süresince 6.552'si ES yapılan naiv papillalı hasta olan toplam 12.893 ERKP işlemi yapıldı. ES yapılan hastaların 81'inde (\%1.24) kanama saptand.. Bu 81 hastanın 46's1 (\%56.8) kadın ve 35’i (\%43.2) erkek idi. Hastaların yaş ortalaması 64.9 (18-89) yıl olarak saptandı. Kanayan hastaların ERKP endikasyonları Tablo l'de özetlendi. Buna göre en sık endikasyonlar sırasıyla koledok taşı ve malign biliyer darlık idi. Isslemi öncesi 22 (\%27.2) hastada kolanjit ve 2 (\%2.4) hastada akut biliyer pankreatit vardı. Hastaların bazal laboratuvar düzeyleri Tablo 2'de gösterildi. Hastaların 1l'nin (\%13.6) asetilsalisilik asit, 11'nin (\%13.6) düşük molekül ağırlıklı heparin ve 12'sinin (\% 14.8) non steroid anti-inflamatuvar ilaç (NSAiI) kullandığı belirlendi. Ön kesi 15 (\%18.5) ve koledoğun balon ile dilatasyonu 2 (\%2.4) hastada uygulandı. Periampüller divertikül 14 (\%17.3) hastada saptandı. Ayrıca, son dönem böbrek yetmezliği nedeniyle hemodiyalize giren $1(\% 1,2)$ hasta ve kompanse karaciğer sirozu olan 1 $(\% 1,2)$ hasta vardı.

Erken kanama 50 (\%61.7) ve geç kanama 31 (\% 38.3) hastada saptandı. Kanama derecesi, 53 (\%65.4) hastada hafif, 21 (\%25.9) hastada orta ve 7 (\%8.6) hastada şiddetli bulundu. Hemoglobinde düşme miktarı 53 (\%65.4) hastada <3 gr/ dL iken, 28 (\%34.6) hastada $\geq 3 \mathrm{gr} / \mathrm{dL}$ saptandı. Hastaların 28 'ine (\%34.6) eritrosit süspansiyon transfüzyonu yapılırken, 53'ünde (\%65.4) transfüzyon ihtiyacı olmadı. Eritrosit süs-

Tablo 1. Kanayan hastaların endoskopik retrograt kolanjiyopankreatografi endikasyonları

$\begin{array}{lcc}\text { Endikasyon } & \text { Sayı } & \text { Yüzde } \\ \text { Koledok taşı } & 58 & 71.6 \\ \text { Bening biliyer darlık } & 7 & 8.6 \\ \text { Malign biliyer darlık } & 14 & 17.3 \\ \text { Safra kaçağı } & 2 & 2.4\end{array}$




\begin{tabular}{|c|c|c|c|c|c|}
\hline & Ortalama & Standart Sapma & Minumum & Maksimum & Normal Aralık \\
\hline Alanin aminotransferaz (U/L) & 102 & 109 & 8 & 496 & $<32$ \\
\hline Aspartat aminotransferaz (U/L) & 102 & 116 & 13 & 570 & $<33$ \\
\hline Gama glutamil transferaz (U/L) & 247 & 221 & 10 & 1210 & $5-36$ \\
\hline Alkalen fosfataz (U/L) & 279 & 279 & 62 & 1658 & $35-105$ \\
\hline Total bilirübin (mg/dL) & 4 & 8.5 & 0.24 & 38 & $<1,2$ \\
\hline Amilaz (U/L) & 71 & 109 & 20 & 1024 & $28-100$ \\
\hline Kreatinin (mg/dL) & 0.8 & 0.72 & 0.39 & 5.6 & $0.5-1.2$ \\
\hline INR $(\mathrm{IS}=1,02)$ & 1.1 & 0.14 & 0.81 & 1.43 & $0.83-1.25$ \\
\hline Lökosit (103/uL) & 8.5 & 5 & 1.75 & 30 & $3.9-11.7$ \\
\hline Trombosit (103/uL) & 232 & 82 & 62 & 451 & $150-440$ \\
\hline Hemoglobin (gr/dL) & 13.3 & 1.18 & 8.7 & 15.8 & $12-15.5$ \\
\hline
\end{tabular}

INR: International normalized ratio

pansiyon transfüzyonu yapılan 28 hastanın 2l'ine (\%25.9) $\leq 4$ ünite ve 7 'sine (\%8.6) $\geq 5$ ünite transfüzyon yapıldı. Endoskopik tedavi olarak hastalarm 4l'ine (\%50.6) epinefrin enjeksiyonu, 25'ine (\%30.8) epinefrin enjeksiyonu ile heater prob kombinasyonu, 7'sine (\%8.6) heater prob, 2'sine (\%2.4) sedece balon tamponadı, 3'üne (\%3.7) balon tamponadı ile epinefrin enjeksiyon kombinasyonu, 2'sine (\%2.4) tam kaplı metalik stent ve l'ine (\%1.2) hemoklips uygulandı. Ilk endoskopik tedavide sedece epinefrin enjeksiyonu uygulanan 2 (\%2.4) ve epinefrin enjeksiyonu ile heater prob kombinasyonu uygulanan 1 (\%1.2) hastada tekrar kanama saptandı. Tekrar kanama gelişen hastalara ikinci kez endoskopik tedavi uygulandıktan sonra tekrar kanama olmadı.

Geç kanama saptanan hastalarda (kanama derecesi hafif, orta ve şiddetli olanların sayı/yüzde oranları sırasıyla 10/32.3, 15/48.4 ve 6/19.3), erken kanama saptanan hastalara (kanama derecesi hafif, orta ve şiddetli olanların sayı/yüzde oranları sırasılya, 43/86, 6/12 ve 1/2) göre anlamlı olarak daha şiddetli kanama saptandı (P: 0.001). Bilirübin düzeyi yükseldikçe kanama şiddetinin arttığı (kanama derecesi hafif, orta ve şiddetli olanlarda ortalama total bilirübin düzeyi $3.65 \mathrm{mg} /$ $\mathrm{dL}, 4 \mathrm{mg} / \mathrm{dL}$ ve $11.6 \mathrm{mg} / \mathrm{dL}$ ) belirlendi (P: 0.047). Ancak diğer laboratuvar düzeyleri ile kanama şiddeti arasında anlamlı bir ilişki bulunmadı. Malign biliyer darlı̆̆ı olan hastalarda (kanama derecesi hafif, orta ve şiddetli olanların sayı/yüzde oranları surasiyla 6/37.5, 6/37.5 ve 4/25, diğer ERKP endikasyonları olan hastalara (kanama derecesi hafif, orta ve şiddetli olanların sayı/yüzde oranları sırasıyla 47/72.3, 15/13.1 ve 3/4.6 ) göre kanama derecesi anlamlı olarak daha şiddetli idi (P: 0.02). Hafif ve şiddetli kanama geçiren hastalar arasinda demografik veriler, komorbid durumlar, antikoagülasyon ve antiagregan ilaç kullanımları, kolanjit, periampüller divertikül varlığı ve ön kesi yapılma açısından anlamlı fark bulunmadı. Ayrıca erken ve geç kanama saptanan hastalar arasında demografik veriler, laboratuvar düzeyleri, komorbid durumlar, antikoagülasyon ve antiagregan ilaç kullanımları, ERKP endikasyonları, kolanjit, periampüller divertikül varlığı ve ön kesi yapılma açısından anlamlı fark yoktu. ES kanaması gelişen bu hastalarda cerrahi gereksinim ve mortalite olmadı.

\section{TARTIŞMA}

Iki dekat önce bildirilen birçok çalışmada ES sonrası kanama insidansı \%2-5 oranında rapor edilmiştir (5). Yakın tarihli prospektif çalışmalarda ise daha düşük oranlarda (\%1-2) bildirilmiştir (7-14). 1987 ve 2003 ylları arasında 16.855 hastayı kapsayan 21 prospektif çalışmanın oluşturduğu bir derlemede, toplam $226(\% 1,3)$ ES sonrası kanama raporlanmıştır (6). Çalışmamızda ES sonrası kanama oranı \% 1.23 ile son ylllarda bildirilen oranlar uyumlu bulundu.

Üç çalışmanın çok değişkenli analizlerine göre işlem öncesi koagülopati, işlem sonrası üç gün içinde antikoagülan kullanımı, işlem öncesi kolanjit, işlem sırasında kanama ve deneyimsiz endoskopist ES sonrası kanama için risk faktörleridir (7-9). ERKP yapılan 4.561 hastanın katıldığı çok merkezli bir çalışmada ise hemodiyaliz, işlem sırasında görünür kanama, yüksek bilirübin ve sfinkterotomi için "pure-cut" akım kullanımı ES sonrası kanama ile ilişkili bulunmuştur (13). Bazı çalışmalarda ön kesi ile ES'nin kanamayı arttırdığı bildirilmiştir (8). Periampüller divertikülün kanama ile ilişkisi bakımından bazı çalışmalarda çelişkili sonuçlar bildirilse de çoğu çalışmada ilişkili bulunmamıştır $(7,9,15)$. Çalışmamızda ise ES sonrası kanaması olan hastaların \%17,3'ünde periampüller divertikül saptandı. Bu oran ERKP uygulanan hastalarda rastlanan periampüller divertikül oranlarına (\%10-20) ben- 
zerdi $(16,17)$. Yapılan kesi uzunluğu ve asetilsalisilik asit veya NSAII'lerin işlem öncesi kullanımı kanamanın önemli belirleyicileri olmadığı raporlanmıştır (7). Merkezimizde tüm ERKP işlemleri deneyimli endoskopistler tarafından yapılmaktadır. Işlem sırasında koagülopatisi olan veya antikoagülan kullanan hastalarda ERKP sadece acil endikasyon durumlarında yapılmaktadır. Bu hastalara ES yapılmadan geçici tedavi olarak nazobiliyer dren ve/veya biliyer stent uygulanmaktadır. Koagülopatisi düzeldikten veya antikoagülan ilaç uygun süre kesildikten sonra ES yapılarak ERKP işlemi tamamlanmaktadır. ERKP işleminden en az 72 saat öncesi warfarin kesilererek düşük molekül ağırlıklı heparin başlanan 10 (\%12.3) hastada ES sonrası kanama belirlendi. Ayrica ES sonrası kanaması olan hastaların 11'i (\%13.6) asetilsalisilik asit ve 12'si (\%14.8) NSAII kullaniyordu.

Çalışmamızda erken ve geç kanama saptanan hastalar arasında demografik veriler, laboratuvar düzeyleri, komorbid durumlar, antikoagülasyon ve/veya antiagregan ilaç kullanımları, ERKP endikasyonları, kolanjit, periampüller divertikül varlığı ve ön kesi yapılma açısından anlamlı fark saptanmadı. $\mathrm{Bu}$ nedenle ES sonrası kanamanın tipini tahmin edebilecek herhangi bir faktör saptamadık. Bilirübin yüksekliği, malign biliyer darlık ve geç kanama saptananlarda şiddetli kanama daha fazla saptandı (sirasiyla P:0.047, P:0.02, P:0.001). Hafif ve şiddetli kanama geçiren hastalar arasında demografik veriler, komorbid durumlar, antikoagülasyon ve/veya antiagregan ilaç kullanımları, kolanjit, periampüller divertikül varlığı ve ön kesi yapılma açısından anlamlı fark bulunmadı.

Klinik olarak anlamlı kanama tespit edildiği andan itibaren medikal ve endoskopik olarak tedavi edilmelidir $(7,10)$. Endoskopik tedavide epinefrin enjeksiyonu, termal ve mekanik yöntemler tek başlarına veya kombinasyon halinde uygulanmaktadır. Literatürde, ES sonrası kanamada epinefrin enjeksiyonu en yaygın kullanılan endoskopik yöntemdir. Iki büyük seride bildirilen vakalarda bu yöntemin başarı oranı \%97.5-100 olarak bildirilmiştir $(18,19)$. Elektrokoter ve heater prob kullanılarak yapılan termal yöntemin ES sonrası kanama kontorolünde tek başına etkili olduğu bildirilmiștir $(20,21)$. Mekanik yöntemlerden balon tamponadı, standart taş çıkarma balon kateteri ile yapılabilmektedir $(7,22)$. Ancak bu yöntemin etkinliği iyi bilinmemektedir. Epinefrin enjeksiyon tedavisi başarısız ya da kanama tekrarında bir veya daha fazla hemoklips kanama yerine uygulanabilmektedir $(23,24)$. Ancak hemoklipsleri aktif kanama ortamına yan görüşlü endoskop ile uygulamak zor olmaktadır. Ayrıca, hemoklipsler yanlışlıkla pankreas orifisine uygulanarak pankreatite neden olabilmektedir. Son zamanlarda mekanik yöntem olarak tam kaplı metalik stentin geçici şekilde uygulanması ile başarılı sonuçlar elde edilmişsir (25). Çalışmamızda epinefrin enjeksiyonu 41 hastada tek başına ve 28 hastada kombinasyon şeklinde kullanılan en yaygın yöntemdi. Heater probu tek başına 7, kombinasyon halinde 25 hastada kullanılan ikinci en sık yöntemdi. Mekanik yöntemlerden balon tamponadı 5 hastaya (tek başın 2 ve epinefrin enjeksiyonu ile 3 hastada), hemoklips 1 hastaya ve tam kaplı metalik stent 2 hastaya uyguland. Ilk endoskopik tedaviden sonra sadece 3 hastada tekrar kanama gelişti.

Çalışmamızın bazı sınırlandırmaları mevcuttu. Öncelikle çalışmamız retrospektif bir çalışmadır. Ancak, ERKP ünitemizde hastaların verileri kayıt defterinde ve bilgisayar ortammda iyi saklanmaktadır. Ikinci olarak çalısmamızda kontrol grubu olmadığı için ES sonrası kanama ile ilişkili risk faktörlerinin etkileri tam olarak analiz edilemedi.

Özetle ERKP, pankreatobiliyer hastalıklarda etkin bir tanı ve tedavi aracı olmakla beraber ciddi komplikasyonlara sahip olan invaziv bir endoskopik işlemdir. Komplikasyonları minimuma indirmek için ERKP endikasyonu doğru konulmalı ve işlem tecrübeli ekipler tarafından yapılmalıdır. Buna rağmen komplikasyonları tamamen önlemek mümkün değildir. ERKP işleminin önemli komplikasyonlarından biri olan kanama, eski çalışmalara göre günümüzde insidansı azalmakla birlikte halen önemi devam etmektedir. Çalışmamızda, son yllarda literatürde bildirilen oranlara benzer oranda $(\% 1,23)$ ES sonrası kanama saptandı. ES sonrası kanamada, çalışmamızda olduğu gibi erken tanı konularak zamanında gerekli tedavilerin uygulanması ile morbidite ve mortalite ciddi şekilde azalmaktadır.

\section{KAYNAKLAR}

1. McCune WS, Shorb PE, Moscovitz H. Endoscopic cannulation of the ampulla of Vater: a preliminary report. Ann Surg 1968;167:752-6

2. Maple JT, Ben-Menachem T, Anderson MA, et al. The role of endoscopy in the evaluation of suspected choledocholithiasis. Gastrointest Endosc 2010;71:1-9.

3. Baron TH, Mallery JS, Hirota WK, et al. The role of endoscopy in the evaluation and treatment of patients with pancreaticobiliary malignancy. Gastrointest Endosc 2003;58:643-9.

4. Costamagna G, Shah SK, Tringali A. Current management of postoperative complications and benign biliary strictures. Gastrointest Endosc Clin N Am 2003;13:635-48.

5. Cotton PB, Lehman G, Vennes J, et al. Endoscopic sphincterotomy complications and their management: an attempt at consensus. Gastrointest Endosc 1991;37:383-93.

6. Andriulli A, Loperfido S, Napolitano G, et al. Incidence rates of post-ERCP complications: a systematic survey of prospective studies. Am J Gastroenterol 2007;102:1781-8.

7. Freeman ML, Nelson DB, Sherman S, et al. Complications of endoscopic biliary sphincterotomy. N Engl J Med 1996;335:909-18.

8. Masci E, Toti G, Mariani A, et al. Complications of diagnostic and therapeutic ERCP: a prospective multicenter study. Am J Gastroenterol 2001;96:417-23. 
9. Loperfido S, Angelini G, Benedetti G, et al. Major early complications from diagnostic and therapeutic ERCP: a prospective multicenter study. Gastrointest Endosc 1998;48:1-10.

10. Rabenstein T, Schneider HT, Hahn EG, et al. 25 years of endoscopic sphincterotomy in Erlangen: assessment of the experience in $3498 \mathrm{pa}-$ tients. Endoscopy 1998;30:A194-201.

11. Vandervoort J, Soetikno RM, Tham TC, et al. Risk factors for complications after performance of ERCP. Gastrointest Endosc 2002; 56:652-6.

12. Christensen M, Matzen P, Schulze S, et al. Complications of ERCP: a prospective study. Gastrointest Endosc 2004; 60:721.

13. Williams EJ, Taylor S, Fairclough P, et al. Risk factors for complication following ERCP; results of a large-scale, prospective multicenter study. Endoscopy 2007; 39:793.

14. Wang P, Li ZS, Liu F, et al. Risk factors for ERCP-related complications: a prospective multicenter study. Am J Gastroenterol 2009; 104:31.

15. Parlak E, Suna N, Kuzu UB, et al. Diverticulum With Papillae: Does Position of Papilla Affect Technical Success? Surg Laparosc Endosc Percutan Tech 2015;25:395-8.

16. Osnes M, Lotveit $T$, Larson $S$, et al. Duodenal diverticula and their relationship to age, sex, and biliary calculi. Scand J Gastroenterol 1981;16:103-7.

17. Mesh E, Friedman E, Czerniak A, et al. The association of biliary and pancreatic anomalies with periampullary duodenal diverticula. Arch Surg 1987;122:1055-7.
18. Leung JW, Chan FK, Sung JJ, et al. Endoscopic sphincterotomy-induced hemorrhage: a study of risk factors and the role of epinephrine injection. Gastrointest Endosc 1995; 42: 550-554

19. Wilcox CM, Canakis J, Mönkemüller KE, et al. Patterns of bleeding after endoscopic sphincterotomy, the subsequent risk of bleeding, and the role of epinephrine injection. Am J Gastroenterol 2004 Feb;99:244-8.

20. S. Kuran S, Parlak E, Oguz D, et al. Endoscopic sphincterotomy-induced hemorrhage: treatmen with heat probe. Gastrointest Endosc 2006;63(3):506-11.

21. Sherman S, Hawes RH, Nisi R, et al. Endoscopic sphincterotomy-induced hemorrhage: treatment with multipolar electrocoagulation. Gastrointest Endosc 1992;38:123-6.

22. Mosca S, Galasso G. Immediate and late bleeding after endoscopic sphincterotomy. Endoscopy. 1999;31:278-9.

23. Baron TH, Norton ID, Herman L. Endoscopic hemoclip placement for post-sphincterotomy bleeding. Gastrointest Endosc 2000; 52:662.

24. Katsinelos P, Paroutoglou G, Beltsis A, et al. Endoscopic hemoclip placement for postsphincterotomy bleeding refractory to injection therapy: report of two cases. Surg Laparosc Endosc Percutan Tech. 2005;15:23840.

25. Shah JN, Marson F, Binmoeller KF. Temporary self-expandable metal stent placement for treatment of post-sphincterotomy bleeding. Gastrointest Endosc. 2010;72:1274-8. 